Pacific Journal of Mathematics

INTEGRABILITY THEOREMS FOR POWER SERIES
EXPANSIONS OF TWO VARIABLES 


\title{
INTEGRABILITY THEOREMS FOR POWER SERIES EXPANSIONS OF TWO VARIABLES
}

\author{
YoSHIMITHU HASEGAWA
}

Let $f(x, y)=\sum_{m, n=0}^{\infty} a_{m, n} x^{m} y^{n}$ in the triangle $x+y \leqq 1$, $x, y \geqq 0$, or in the quarter-disk $x^{2}+y^{2}<1, x, y \geqq 0$. This paper show some relations between $L$-integrability of $f(x, y)$, with certain multipliers, and the coefficients $a_{m, n}$.

1. Definition. A real-valued function $f(x, y)$ is said to be harmonic in a domain $D$ in $R^{2}$ if it is 2-times continuously differentiable in $D$ and satisfies Laplace's equation

$$
\Delta f \equiv \frac{\partial^{2} f}{\partial x^{2}}+\frac{\partial^{2} f}{\partial y^{2}}=0 \quad \text { for any }(x, y) \in D .
$$

Throughout the paper, the letter $C$, with or without a suffix, denotes a positive constant, not necessarily the same at each appearance.

Heywood [3] proved a result as follows:

Suppose that $f(x)=\sum_{n=0}^{\infty} a_{n} x^{n}$ for $0 \leqq x<1$, that $\gamma<1$, and that there are positive numbers $\varepsilon, C$ such that $a_{n} \geqq-C n^{-(\gamma+\varepsilon)}$ for all sufficiently large $n$. Then $(1-x)^{-r} f(x) \in L(0,1)$ if and only if $\sum_{n=1}^{\infty} n^{r-1} a_{n}$ converges absolutely.

We shall show two analogues of his result for power series expansions of two variables.

Kiselman [4] proved the following theorem.

THEOREM A. If $f(x, y)$ is harmonic in the disk $x^{2}+y^{2}<r_{0}^{2}$ $\left(r_{0}>0\right)$, but not in any open disk of larger radius centred on the origin, then the power series expansion

$$
f(x, y)=\sum_{m, n=0}^{\infty} a_{m, n} x^{m} y^{n}
$$

converges absolutely in the square $K:|x|+|y|<r_{0}$, uniformly on every compact subset of $K$. It diverges at all points exterior to $K$ for which $x \neq 0$, and $y \neq 0$.

Further, the following theorem is known (see [2, p. 189 and 200] and [4]).

THEOREM B. Suppose that $f(x, y)$ is harmonic in the disk

$$
x^{2}+y^{2}<r_{0}^{2},
$$


and that $f(x, y)$ has the power series expansion (1) in the square $K$, where $K$ is defined as in Theorem $A$. Let $P_{N}(x, y)$ be defined by

$$
P_{N}(x, y)=\sum_{m+n=N} a_{m, n} x^{m} y^{n} \quad(N=0,1,2, \cdots) .
$$

Then the polynomial expansion

$$
f(x, y)=\sum_{N=0}^{\infty} P_{N}(x, y)
$$

of $f(x, y)$ converges uniformly and absolutely in $x^{2}+y^{2} \leqq r^{2}$ for any $0<r<r_{0}$, where $P_{N}(x, y)$ are harmonic.

We give the following four theorems.

THEorem 1. Suppose that a double power series (1) converges absolutely in the triangle

$$
T: x+y<1
$$$$
x, y \geqq 0,
$$

that $\gamma<1$, and that there are positive numbers $\varepsilon, C$ such that

$$
a_{m, n} \geqq-C(m+n+1)^{m+n-\gamma-\varepsilon+1 / 2}(m+1)^{-(m+1 / 2)}(n+1)^{-(n+1 / 2)}
$$

for all sufficiently large $m+n$. Then $(1-x-y)^{-r} f(x, y)$ is Lebesgueintegrable on $T$ if and only if

$$
\sum_{m, n=0}^{\infty}(m+n+1)^{-m-n+\gamma-5 / 2}(m+1)^{m+1 / 2}(n+1)^{n+1 / 2} a_{m, n}
$$

converges absolutely.

THEOREM 2. Suppose that $f(x, y)$ is harmonic in the quarter-disk

$$
Q: x^{2}+y^{2}<1, \quad x, y \geqq 0,
$$

and that $f(x, y)$ has the power series expansion (1) in the triangle $T$, where $T$ is defined by (2). Then, under the assumption (3), the function $(1-x-y)^{-\gamma} f(x, y), \gamma<1$, is Lebesgue-integrable on $T$ if and only if the series (4) converges absolutely.

Theorem 2 is an obvious consequence of Theorem $\mathrm{A}\left(r_{0}=1\right)$ and Theorem 1, and so we omit the proof.

THEOREM 3. Suppose that a double power series (1) converges absolutely in the quarter-disk $Q$, where $Q$ is defined by (5), that $\gamma<1$, and that there are positive numbers $\varepsilon, C$ such that 


$$
a_{m, n} \geqq\left\{\begin{array}{c}
-C(m+n+1)^{(m+n+1) / 2-\gamma-\varepsilon}(m+1)^{-(m+1) / 2} \\
\times(n+1)^{-(n+1) / 2} \\
-C(m+n+1)^{(m+n) / 2-\gamma-\varepsilon}(m+1)^{-m / 2} \\
\left.\times(n+1)^{-(n+1) / 2} \quad \text { (odd } m \text { and even } n\right) \\
-C(m+n+1)^{(m+n) / 2-\gamma-\varepsilon}(m+1)^{-(m+1) / 2} \\
\times(n+1)^{-n / 2} \quad(\text { even } m, n) \\
-C(m+n+1)^{(m+n-1) / 2-\gamma-\varepsilon}(m+1)^{-m / 2} \\
\times(n+1)^{-n / 2}
\end{array}\right.
$$

for all sufficiently large $m+n$. Then the function

$$
\left\{1-\left(x^{2}+y^{2}\right)^{1 / 2}\right\}^{-\gamma} f(x, y)
$$

is Lebesgue-integrable on $Q$ if and only if the series

$$
\sum_{m, n=0}^{\infty}(m+n+1)^{-(m+n+3) / 2+\gamma}(m+1)^{m / 2}(n+1)^{n / 2} a_{m, n}
$$

converges absolutely.

REMARK 1. In Theorem 3 , it is easily seen that (6) may be replaced by a stronger condition

$$
\begin{aligned}
a_{m, n} \geqq-C(m+n+1)^{(m+n-1) / 2-\gamma-\delta}(m+1)^{-m / 2}(n+1)^{-n / 2} & \\
& (m, n=0,1,2, \cdots)
\end{aligned}
$$

for all sufficiently large $m+n$.

THEOREM 4. Suppose that $f(x, y)$ is harmonic in the quarter-disk $Q$, where $Q$ is defined by (5), and that $f(x, y)$ has the power series expansion (1) in the triangle $T$, where $T$ is defined by (2). Then, under the assumption (6), the function $\left\{1-\left(x^{2}+y^{2}\right)^{1 / 2}\right\}^{-\gamma} f(x, y), \gamma<1$, is Lebesgue-integrable on $Q$ if and only if the series (7) converges absolutely.

Theorem 4 is a consequence of Theorem B $\left(r_{0}=1\right)$ and Theorem 3. In $\S 2$, we shall prove Theorem 1 and give an example for Theorem 2 . Further, in $\S 3$, we shall prove Theorems 3 and 4 .

2. Proof of Theorem 1. First, suppose that $(1-x-y)^{-r} f(x, y)$ is Lebesgue-integrable on $T$. Without loss of generality, we suppose that $\gamma+\varepsilon$ is a noninteger value $<1$. For, we get

$$
a_{m, n} \geqq-C(m+n+1)^{m+n-\gamma-\varepsilon^{\prime}+1 / 2}(m+1)^{-(m+1 / 2)}(n+1)^{-(n+1 / 2)}
$$

for $0<\varepsilon^{\prime}<\varepsilon$. We have, for any $(x, y) \in T$, 


$$
\begin{aligned}
(1-x-y)^{\gamma+\varepsilon-1}= & \sum_{N=0}^{\infty} \frac{\Gamma(N+1-\gamma-\varepsilon)}{\Gamma(N+1) \Gamma(1-\gamma-\varepsilon)}(x+y)^{N} \\
= & \frac{1}{\Gamma(1-\gamma-\varepsilon)} \sum_{N=0}^{\infty} \frac{\Gamma(N+1-\gamma-\varepsilon)}{\Gamma(N+1)} \\
& \times \sum_{\substack{m+n=N \\
m, n \geqq 0}}\left(\begin{array}{c}
m+n \\
n
\end{array}\right) x^{m} y^{n} \\
= & \frac{1}{\Gamma(1-\gamma-\varepsilon)} \sum_{m, n=0}^{\infty} \frac{\Gamma(m+n-\gamma-\varepsilon+1)}{\Gamma(m+1) \Gamma(n+1)} x^{m} y^{n} \\
= & \frac{1}{\Gamma(1-\gamma-\varepsilon)} \sum_{m, n=0}^{\infty} b_{m, n} x^{m} y^{n},
\end{aligned}
$$

say, where $\Gamma(u)$ is the Gamma function. By Stirling's formula (see e.g. $[1$, p. 24])

$$
\Gamma(u)=\sqrt{2 \pi} u^{u-1 / 2} e^{-u+\eta / 12 u} \quad \text { for any } u>0,
$$

where $\eta$ is a number independent of $u$ between 0 and 1 , we obtain

$$
C_{1} u^{u-1 / 2} e^{-u} \leqq \Gamma(u) \leqq C_{2} u^{u-1 / 2} e^{-u} \quad \text { for any } u \geqq u_{0}
$$

if $u_{0}$ is a fixed positive number. Hence we get easily

$$
C_{3} \lambda_{m, n} \leqq b_{m, n} \leqq C_{4} \lambda_{m, n} \quad \text { for all } m, n \geqq 0,
$$

where

$$
\lambda_{m, n}=(m+n+1)^{m+n-\gamma-\varepsilon+1 / 2}(m+1)^{-\langle m+1 / 2)}(n+1)^{-(n+1 / 2)}
$$

(notice $u_{0} \geqq \min (1-\gamma-\varepsilon, 1)$ ). Let

$$
g(x, y)=C_{5} \Gamma(1-\gamma-\varepsilon)(1-x-y)^{\gamma+\varepsilon-1}, \quad C_{5} \geqq C / C_{3} .
$$

Then, it is clear that $(1-x-y)^{-r} g(x, y)$ is Lebesgue-integrable on $T$. Thus, by assumption,

$$
\begin{aligned}
(1-x-y)^{-r}\{f(x, y)+g(x, y)\}= & (1-x-y)^{-r} \\
& \times \sum_{m, n=0}^{\infty}\left(a_{m, n}+C_{5} b_{m, n}\right) x^{m} y^{n}
\end{aligned}
$$

is Lebesgue-integrable on T. By (3) and (10), we heve

$$
a_{m, n}+C_{5} b_{m, n} \geqq a_{m, n}+C \lambda_{m, n} \geqq 0
$$

for all sufficiently large $m+n$. Hence we get

$$
\begin{aligned}
\iint_{T}(1-x-y)^{-\gamma} & \left\{\sum_{m, n=0}^{\infty}\left(a_{m, n}+C_{5} b_{m, n}\right) x^{m} y^{n}\right\} d x d y \\
= & \sum_{m, n=0}^{\infty}\left(a_{m, n}+C_{5} b_{m, n}\right) \iint_{T}(1-x-y)^{-\tau} x^{m} y^{n} d x d y,
\end{aligned}
$$


where the right-side series converges absolutely. Using the change of variable $x=(1-y) u$, we have, for all $m, n \geqq 0$,

$$
\begin{aligned}
\iint_{T}(1-x- & -y)^{-\gamma} x^{m} y^{n} d x d y \\
& =\int_{0}^{1} d y \int_{0}^{1-y}(1-x-y)^{-\gamma} x^{m} y^{n} d x \\
& =\int_{0}^{1}(1-y)^{m+1-\gamma} y^{n} d y \int_{0}^{1}(1-u)^{-\gamma} u^{m} d u \\
& =\frac{\Gamma(n+1) \Gamma(m+2-\gamma)}{\Gamma(m+n+3-\gamma)} \cdot \frac{\Gamma(m+1) \Gamma(1-\gamma)}{\Gamma(m+2-\gamma)} \\
& =\Gamma(1-\gamma) \cdot \frac{\Gamma(m+1) \Gamma(n+1)}{\Gamma(m+n+3-\gamma)} .
\end{aligned}
$$

Hence, from (9), we get

$$
\begin{aligned}
C_{6}(m+n+ & 1)^{-m-n+\gamma-5 / 2}(m+1)^{m+1 / 2}(n+1)^{n+1 / 2} \\
& \leqq \iint_{T}(1-x-y)^{-\gamma} x^{m} y^{n} d x d y \\
& \leqq C_{7}(m+n+1)^{-m-n+\gamma-5 / 2}(m+1)^{m+1 / 2}(n+1)^{n+1 / 2}
\end{aligned}
$$

for all $m, n \geqq 0$. Thus, by (11) and (12),

$$
\sum_{m, n=0}^{\infty}(m+n+1)^{-m-n+\gamma-5 / 2}(m+1)^{m+1 / 2}(n+1)^{n+1 / 2}\left(a_{m, n}+C_{5} b_{m, n}\right)
$$

converges absolutely. Further, from (10)

$$
\begin{array}{r}
\sum_{m, n=0}^{\infty}(m+n+1)^{-m-n+\gamma-5 / 2}(m+1)^{m+1 / 2}(n+1)^{n+1 / 2} b_{m, n} \\
\leqq C_{4} \sum_{m, n=0}^{\infty}(m+n+1)^{-2-\varepsilon}<\infty .
\end{array}
$$

By (3) and (10), we get

$$
\left|a_{m, n}\right| \leqq a_{m, n}+2 C \lambda_{m, n} \leqq a_{m, n}+2 C_{5} b_{m, n} \quad\left(C_{5} \geqq C / C_{3}\right)
$$

for all sufficiently large $m+n$. Hence, from (13) and (14), the series (4) converges absolutely.

Conversely we suppose that the series (4) converges absolutely, and will deduce that $(1-x-y)^{-r} f(x, y)$ is Lebesgue-integrable on $T$. For this part of the argument we do not assume (3). We have in fact 


$$
\begin{aligned}
\iint_{T} & (1-x-y)^{-\gamma}|f(x, y)| d x d y \\
& \leqq \iint_{T}(1-x-y)^{-\gamma}\left\{\sum_{m, n=0}^{\infty}\left|a_{m, n}\right| x^{m} y^{n}\right\} d x d y \\
& =\sum_{m, n=0}^{\infty}\left|a_{m, n}\right| \iint_{T}(1-x-y)^{-\gamma} x^{m} y^{n} d x d y \\
& \leqq C_{7} \sum_{m, n=0}^{\infty}(m+n+1)^{-m-n+\gamma-5 / 2}(m+1)^{m+1 / 2}(n+1)^{n+1 / 2}\left|a_{m, n}\right|<\propto
\end{aligned}
$$

by (12). Thus Theorem 1 is proved.

EXAMPLE FOR THEOREM 2. Let

$$
f(x, y)=\Re(1-z)^{-2}=\frac{(1-x)^{2}-y^{2}}{\left\{(1-x)^{2}+y^{2}\right\}^{2}} \quad(z=x+i y, i=\sqrt{-1}) .
$$

Then $f(x, y)$ is harmonic in the disk $x^{2}+y^{2}<1$. Since

$$
f(x, y)=\Re \sum_{N=0}^{\infty}(N+1) z^{N}=\sum_{N=0}^{\infty}(N+1) \sum_{m+2 n=N}(-1)^{n}\left(\begin{array}{c}
m+2 n \\
2 n
\end{array}\right) x^{m} y^{2 n}
$$

in the disk $x^{2}+y^{2}<1$, we get

$$
f(x, y)=\sum_{m, n=0}^{\infty}(-1)^{n} \frac{\Gamma(m+2 n+2)}{\Gamma(m+1) \Gamma(2 n+1)} x^{m} y^{2 n}
$$

in the square $|x|+|y|<1$, by Theorem A. When $a_{m, n}$ denote the $(m, n)$ th coefficients of this power series expansion, we have, from (9),

$$
\begin{aligned}
C_{1}(m+ & 2 n+1)^{m+2 n+3 / 2}(m+1)^{-(m+1 / 2)}(2 n+1)^{-(2 n+1 / 2)} \\
& \leqq\left|a_{m, 2 n}\right| \leqq C_{2}(m+2 n+1)^{m+2 n+3 / 2}(m+1)^{-(m+1 / 2)}(2 n+1)^{-(2 n+1 / 2)}
\end{aligned}
$$

and $a_{m, 2 n+1}=0$. First we put $\gamma<-1$. Then the sequence $\left\{a_{m, n}\right\}$ satisfies (3) for $\varepsilon=-(\gamma+1) / 2$. Now we have

$$
\begin{aligned}
& \iint_{T}(1-x-y)^{-\gamma}|f(x, y)| d x d y \\
= & \int_{0}^{1}(1-x)^{-\gamma-1} d x \int_{0}^{1} \frac{(1-u)^{-\gamma+1}(1+u)}{\left(1+u^{2}\right)^{2}} d u<\infty
\end{aligned}
$$

by the change of variable $y=(1-x) u$. Further we get

$$
\begin{array}{r}
\sum_{m, n=0}^{\infty}(m+n+1)^{-m-n+\gamma-5 / 2}(m+1)^{m+1 / 2}(n+1)^{n+1 / 2}\left|a_{m, n}\right| \\
\leqq C_{2} \sum_{m, n=0}^{\infty}(m+n+1)^{\gamma-1}<\infty
\end{array}
$$

Next we set $\gamma=-1$. Then $\left\{a_{m, n}\right\}$ does not satisfy (3), but we notice $\varepsilon=0$. It is clear that 


$$
\iint_{T}(1-x-y)|f(x, y)| d x d y=\int_{0}^{1} \frac{(1-u)^{2}(1+u)}{\left(1+u^{2}\right)^{2}} d u<\infty .
$$

But we get

$$
\begin{aligned}
\sum_{m, n=0}^{\infty}(m & +n+1)^{-m-n-7 / 2}(m+1)^{m+1 / 2}(n+1)^{n+1 / 2}\left|a_{m, n}\right| \\
& \geqq C_{1} \sum_{m, n=0}^{\infty}(m+2 n+1)^{-2}>\frac{C_{1}}{4} \sum_{m, n=0}^{\infty}(m+n+1)^{-2}=\infty .
\end{aligned}
$$

Thus this example $(\gamma=-1)$ show that we cannot set $\varepsilon=0$ in (3) without destroying the validity of Theorem 2.

3. In order to prove Theorem 3, we need the following lemma.

Lemma. Suppose that $\mu<1$, and that $A(x, y)$ is defined by

$$
A(x, y)=(1+x+y+x y)\left(1-x^{2}-y^{2}\right)^{\mu-1}
$$

in the quarter-disk $Q$, where $Q$ is defined by (5). Then $A(x, y)$ has the power series expansion

$$
A(x, y)=\sum_{m, n=0}^{\infty} d_{m, n} x^{m} y^{n}, \quad C_{1} \delta_{m, n} \leqq d_{m, n} \leqq C_{2} \delta_{m, n} \quad\left(C_{1}, C_{2}>0\right)
$$

in $Q$, where

$$
\delta_{m, n}=\left\{\begin{array}{cr}
(m+n+1)^{(m+n+1) / 2-\mu}(m+1)^{-(m+1) / 2} & \\
\times(n+1)^{-(n+1) / 2} & \\
(m+n+1)^{(m+n) / 2-\mu}(m+1)^{-m / 2} & \\
\times(n+1)^{-(n+1) / 2} & \text { (oven } m, n) \\
(m+n+1)^{(m+n) / 2-\mu}(m+1)^{-(m+1) / 2} & \\
\times(n+1)^{-n / 2} & (\text { even } m \text { and } \text { and odd } n) \\
(m+n+1)^{(m+n-1) / 2-\mu}(m+1)^{-m / 2} & \\
\times(n+1)^{-n / 2} &
\end{array}\right.
$$

Proof. We have, for any $(x, y) \in Q$,

$$
\begin{aligned}
\left(1-x^{2}-y^{2}\right)^{\mu-1} & =\sum_{N=0}^{\infty} \frac{\Gamma(N+1-\mu)}{\Gamma(N+1) \Gamma(1-\mu)}\left(x^{2}+y^{2}\right)^{N} \\
& =\sum_{N=0}^{\infty} \frac{\Gamma(N+1-\mu)}{\Gamma(N+1) \Gamma(1-\mu)} \sum_{\substack{m+n=N \\
m, n \geq 0}}\left(\begin{array}{c}
m+n \\
m
\end{array}\right) x^{2 m} y^{2 n} \\
& =\sum_{m, n=0}^{\infty} \frac{1}{\Gamma(1-\mu)} \cdot \frac{\Gamma(m+n+1-\mu)}{\Gamma(m+1) \Gamma(n+1)} x^{2 m} y^{2 n} \\
& =\sum_{m, n=0}^{\infty} p_{m, n} x^{2 m} y^{2 n}
\end{aligned}
$$


say. Then we get

$$
A(x, y)=\sum_{m, n=0}^{\infty} p_{m, n}\left(x^{2 m} y^{2 n}+x^{2 m+1} y^{2 n}+x^{2 m} y^{2 n+1}+x^{2 m+1} y^{2 n+1}\right) .
$$

We put

$$
d_{m, n}= \begin{cases}p_{m / 2, n / 2} & (\text { even } m, n) \\ p_{(m-1) / 2, n / 2} & (\text { odd } m \text { and even } n) \\ p_{m / 2,(n-1) / 2} & (\text { even } m \text { and odd } n) \\ p_{(m-1) / 2,(n-1) / 2} & (\text { odd } m, n) .\end{cases}
$$

Now, from (16) and (9), we get easily (15). Thus the Lemma is proved.

Proof of Theorem 3. First, suppose that $\left\{1-\left(x^{2}+y^{2}\right)^{1 / 2}\right\}^{-\gamma} f(x, y)$ is Lebesgue-integrable on $Q$. Without loss of generality, we may suppose that $\gamma+\varepsilon$ is a noninteger $<1$. Let

$$
h(x, y)=(1+x+y+x y)\left(1-x^{2}-y^{2}\right)^{\gamma+\varepsilon-1}
$$

in $Q$. Then, by the Lemma $(\mu=\gamma+\varepsilon)$, we have

$$
h(x, y)=\sum_{m, n=0}^{\infty} k_{m, n} x^{m} y^{n}, \quad C_{1} \theta_{m, n} \leqq k_{m, n} \leqq C_{2} \theta_{m, n}
$$

in $Q$, where $k_{m, n}$ and $\theta_{m, n}$ are defined respectively like $d_{m, n}$ and $\delta_{m, n}$ in the Lemma with $\mu=\gamma+\varepsilon$. Clearly, the function

$$
\begin{aligned}
& \left\{1-\left(x^{2}+y^{2}\right)^{1 / 2}\right\}^{-\gamma} h(x, y) \\
= & (1+x+y+x y)\left\{1+\left(x^{2}+y^{2}\right)^{1 / 2}\right\}^{\gamma+\varepsilon-1}\left\{1-\left(x^{2}+y^{2}\right)^{1 / 2}\right\}^{\varepsilon-1}
\end{aligned}
$$

is Lebesgue-integrable on $Q$. Hence, by assumption, the function

$$
\begin{aligned}
\left\{1-\left(x^{2}+y^{2}\right)^{1 / 2}\right\}^{-r} & \left\{f(x, y)+C_{3} h(x, y)\right\} \\
= & \left\{1-\left(x^{2}+y^{2}\right)^{1 / 2}\right\}^{-\gamma} \sum_{m, n=0}^{\infty}\left(a_{m, n}+C_{3} k_{m, n}\right) x^{m} y^{n}
\end{aligned}
$$

is Lebesgue-integrable on $Q$, where $C_{3} \geqq C / C_{1}$. Further, by (6) and (18), we have

$$
a_{m, n}+C_{3} k_{m, n} \geqq a_{m, n}+C \theta_{m, n} \geqq 0
$$

for all sufficiently large $m+n$. Thus we get

$$
\begin{aligned}
\iint_{Q}\{1- & \left.\left(x^{2}+y^{2}\right)^{1 / 2}\right\}^{-\gamma}\left\{\sum_{m, n=0}^{\infty}\left(a_{m, n}+C_{3} k_{m, n}\right) x^{m} y^{n}\right\} d x d y \\
= & \sum_{m, n=0}^{\infty}\left(a_{m, n}+C_{3} k_{m, n}\right) \iint_{Q}\left\{1-\left(x^{2}+y^{2}\right)^{1 / 2}\right\}^{-\gamma} x^{m} y^{n} d x d y,
\end{aligned}
$$


where the right-side series converges absolutely. By the change of variables

$$
x=r \cos v, \quad y=r \sin v \quad(0 \leqq r<1,0 \leqq v \leqq \pi / 2),
$$

we get

$$
\begin{aligned}
\iint_{Q}\{1 & \left.-\left(x^{2}+y^{2}\right)^{1 / 2}\right\}^{-\gamma} x^{m} y^{n} d x d y \\
& =\int_{0}^{1}(1-r)^{-\gamma} r^{m+n+1} d r \int_{0}^{\pi / 2} \sin ^{m} v \cos ^{n} v d v \\
& =\frac{\Gamma(m+n+2) \Gamma(1-\gamma)}{\Gamma(m+n+3-\gamma)} \cdot \frac{1}{2} \cdot \frac{\Gamma((m+1) / 2) \Gamma((n+1) / 2)}{\Gamma((m+n) / 2+1)} .
\end{aligned}
$$

Thus, from (9), we get

$$
\begin{aligned}
C_{4}(m+n+1)^{-(m+n+3) / 2+\gamma}(m+1)^{m / 2}(n+1)^{n / 2} \\
\quad \leqq \iint_{Q}\left\{1-\left(x^{2}+y^{2}\right)^{1 / 2}\right\}^{-\gamma} x^{m} y^{n} d x d y \\
\quad \leqq C_{5}(m+n+1)^{-(m+n+3) / 2+\gamma}(m+1)^{m / 2}(n+1)^{n / 2}
\end{aligned}
$$

for all $m, n \geqq 0$. Hence, by (20),

$$
\sum_{m, n=0}^{\infty}(m+n+1)^{-(m+n+3) / 2+\gamma}(m+1)^{m / 2}(n+1)^{n / 2}\left(a_{m, n}+C_{3} k_{m, n}\right)
$$

converges absolutely. Further, by (18), we have

$$
\begin{aligned}
& \sum_{m, n=0}^{\infty}(m+n+1)^{-(m+n+3) / 2+r}(m+1)^{m / 2}(n+1)^{n / 2} k_{m, n} \\
& \quad \leqq C_{2} \sum_{m, n=0}^{\infty}\left\{(m+n+1)^{-1-\varepsilon}(m+1)^{-1 / 2}(n+1)^{-1 / 2}\right. \\
& +(m+n+1)^{-3 / 2-\varepsilon}(n+1)^{-1 / 2}+(m+n+1)^{-3 / 2-\varepsilon}(m+1)^{-1 / 2} \\
& \left.+(m+n+1)^{-2-\varepsilon}\right\}<\infty .
\end{aligned}
$$

By (6) and (18), we get

$$
\left|a_{m, n}\right| \leqq a_{m, n}+2 C \theta_{m, n} \leqq a_{m, n}+2 C_{3} k_{m, n} \quad\left(C_{3} \geqq C / C_{1}\right)
$$

for all sufficiently large $m+n$. Hence, from (22) and (23), the series (7) converges absolutely.

Conversely we suppose that series (7) converges absolutely, and will deduce that $\left\{1-\left(x^{2}+y^{2}\right)^{1 / 2}\right\}^{-\gamma} f(x, y)$ is Lebesgue-integrable on $Q$. For this part of the argument we do not assume (6). We have in fact 


$$
\begin{aligned}
& \iint_{Q}\left\{1-\left(x^{2}+y^{2}\right)^{1 / 2}\right\}^{-r}|f(x, y)| d x d y \\
& \leqq \iint_{Q}\left\{1-\left(x^{2}+y^{2}\right)^{1 / 2}\right\}^{-r}\left\{\sum_{m, n=0}^{\infty}\left|a_{m, n}\right| x^{m} y^{n}\right\} d x d y \\
& \quad=\sum_{m, n=0}^{\infty}\left|a_{m, n}\right| \iint_{Q}\left\{1-\left(x^{2}+y^{2}\right)^{1 / 2}\right\}^{-r} x^{m} y^{n} d x d y \\
& \leqq C_{5} \sum_{m, n=0}^{\infty}(m+n+1)^{-(m+n+3) / 2+r}(m+1)^{m / 2}(n+1)^{n / 2}\left|a_{m, n}\right|<\infty
\end{aligned}
$$

by (21). Thus Theorem 3 is proved.

REMARK 2. From (17), it is easily seen that

$$
C_{1} h(x, y) \leqq\left\{1-\left(x^{2}+y^{2}\right)^{1 / 2}\right\}^{\gamma+\varepsilon-1} \leqq C_{2} h(x, y)
$$

in $Q$.

Proof of Theorem 4. By Theorem B $\left(r_{0}=1\right)$, we get

$$
f(x, y)=\sum_{N=0}^{\infty} \sum_{m+n=N} a_{m, n} x^{m} y^{n}
$$

in $Q$. We define $h(x, y)$ by (17). Then it is sufficient for us to notice that

$$
\begin{aligned}
f(x, y)+C_{3} h(x, y) & =\sum_{N=0}^{\infty} \sum_{m+n=R} a_{m, n} x^{m} y^{n}+C_{3} \sum_{m, n=0}^{\infty} k_{m, n} x^{m} y^{n} \\
& =\sum_{N=0}^{\infty} \sum_{m+n=N}\left(a_{m, n}+C_{3} k_{m, n}\right) x^{m} y^{n} \\
& =\sum_{m, n=0}^{\infty}\left(a_{m, n}+C_{3} k_{m, n}\right) x^{m} y^{n}
\end{aligned}
$$

in $Q$, in view of (18) and (19), where the last right-side series converges absolutely. Thus Theorem 4 is a consequence of Theorem 3.

The author wishes to thank the referee for several helpful suggestions.

\section{REFERENCES}

1. E. Artin, The Gamma Function, Holt, Rinehart and Winston, New York (1964).

2. M. Brelot, Éléments de la théorie classique du potentiel, Les cours de Sorbonne, 3rd edition, Paris (1965).

3. P. Heywood, Integrability theorems for power series and Laplace transforms (II),

J. London Math. Soc., 32 (1957), 22-27.

4. C. O. Kiselman, Prolongement des solutions d'une équation aux dérivées partielles à coefficients constants, Bull. Soc. Math. France, 97 (1969), 329-356.

Received January 12, 1972 and in revised form July 24, 1972.

HIROSAKI UNIVERSITY, JAPAN 


\section{PACIFIC JOURNAL OF MATHEMATICS}

\section{EDITORS}

D. Gilbarg and J. Milgram

Stanford University

Stanford, California 94305

\author{
R. A. Beaumont \\ University of Washington \\ Seattle, Washington 98105
}

J. DuGUNDJI

Department of Mathematics

University of Southern California

Los Angeles, California 90007

Richard ARENS

University of California

Los Angeles, California 90024

\section{ASSOCIATE EDITORS}
E. F. BECKENBACH
B. H. NeumanN
F. WOLF
K. YosHIDA

\section{SUPPORTING INSTITUTIONS}

UNIVERSITY OF BRITISH COLUMBIA

CALIFORNIA INSTITUTE OF TECHNOLOGY

UNIVERSITY OF CALIFORNIA

MONTANA STATE UNIVERSITY

UNIVERSITY OF NEVADA

NEW MEXICO STATE UNIVERSITY

OREGON STATE UNIVERSITY

UNIVERSITY OF OREGON

OSAKA UNIVERSITY

\author{
UNIVERSITY OF SOUTHERN CALIFORNIA \\ STANFORD UNIVERSITY \\ UNIVERSITY OF TOKYO \\ UNIVERSITY OF UTAH \\ WASHINGTON STATE UNIVERSITY \\ UNIVERSITY OF WASHINGTON
* * * *
AMERICAN MATHEMATICAL SOCIETY \\ NAVAL WEAPONS CENTER
}

The Supporting Institutions listed above contribute to the cost of publication of this Journal, but they are not owners or publishers and have no responsibility for its content or policies.

Mathematical papers intended for publication in the Pacific Journal of Mathematics should be in typed form or offset-reproduced, (not dittoed), double spaced with large margins. Underline Greek letters in red, German in green, and script in blue. The first paragraph or two must be capable of being used separately as a synopsis of the entire paper. The editorial "we" must not be used in the synopsis, and items of the bibliography should not be cited there unless absolutely necessary, in which case they must be identified by author and Journal, rather than by item number. Manuscripts, in duplicate if possible, may be sent to any one of the four editors. Please classify according to the scheme of Math. Rev. Index to Vol. 39. All other communications to the editors should be addressed to the managing editor, Richard Arens, University of California, Los Angeles, California, 90024.

50 reprints are provided free for each article; additional copies may be obtained at cost in multiples of 50 .

The Pacific Journal of Mathematics is issued monthly as of January 1966. Regular subscription rate: $\$ 48.00$ a year (6 Vols., 12 issues). Special rate: $\$ 24.00$ a year to individual members of supporting institutions.

Subscriptions, orders for back numbers, and changes of address should be sent to Pacific Journal of Mathematics, 103 Highland Boulevard, Berkeley, California, 94708.

PUBLISHED BY PACIFIC JOURNAL OF MATHEMATICS, A NON-PROFIT CORPORATION

Printed at Kokusai Bunken Insatsusha (International Academic Printing Co., Ltd.), 270, 3-chome Totsuka-cho, Shinjuku-ku, Tokyo 160, Japan. 


\section{Pacific Journal of Mathematics}

\section{Vol. 46, No. 2 December, 1973}

Christopher Allday, Rational Whitehead products and a spectral sequence of

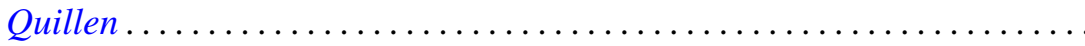

James Edward Arnold, Jr., Attaching Hurewicz fibrations with fiber

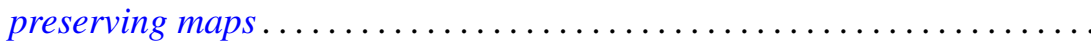

Catherine Bandle and Moshe Marcus, Radial averaging transformations with various metrics.................................

David Wilmot Barnette, A proof of the lower bound conjecture for convex

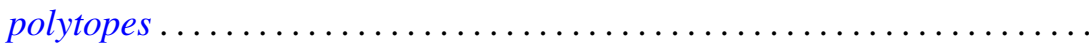

Louis Harvey Blake, Simple extensions of measures and the preservation of

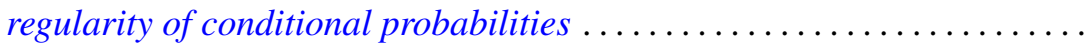

James W. Cannon, New proofs of Bing's approximation theorems for

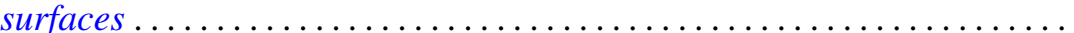

C. D. Feustel and Robert John Gregorac, On realizing HNN groups in

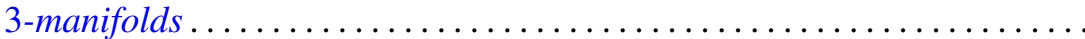

Theodore William Gamelin, Iversen's theorem and fiber algebras . . . . . . . . 389

Daniel H. Gottlieb, The total space of universal fibrations . . . . . . . . . . . .

Yoshimitsu Hasegawa, Integrability theorems for power series expansions of

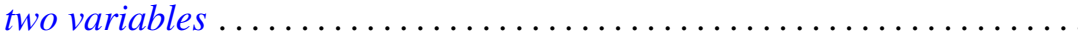

Dean Robert Hickerson, Length of period simple continued fraction expansion of $\sqrt{ } d$

Herbert Meyer Kamowitz, The spectra of endomorphisms of the disc algebra.

Dong S. Kim, Boundedly holomorphic convex domains

Daniel Ralph Lewis, Integral operators on $\mathscr{L}_{p}$-spaces ...

John Eldon Mack, Fields of topological spaces . . . . . . . . .

V. B. Moscatelli, On a problem of completion in bornology

Ellen Elizabeth Reed, Proximity convergence structures. .

Ronald C. Rosier, Dual spaces of certain vector sequence spaces .

Robert A. Rubin, Absolutely torsion-free rings

Leo Sario and Cecilia Wang, Radial quasiharmonic functions . .

James Henry Schmerl, Peano models with many generic classes .

H. J. Schmidt, The $\mathscr{F}$-depth of an $\mathscr{F}$-projector ............

Edward Silverman, Strong quasi-convexity. . . . . . . . . . . . . . . . . 549

Barry Simon, Uniform crossnorms ....................... 555

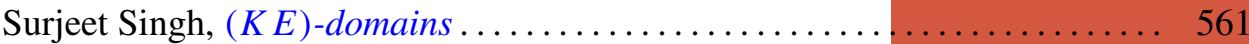

Ted Joe Suffridge, Starlike and convex maps in Banach spaces . . . . . . . . 575

Milton Don Ulmer, $C$-embedded $\Sigma$-spaces . . . . . . . . . . . . . . . . 591

Wolmer Vasconcelos, Conductor, projectivity and injectivity . . . . . . . . . 603 